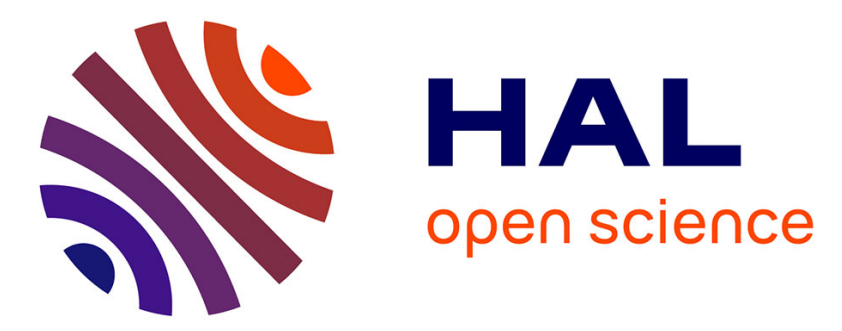

\title{
Comparative finite element analysis of skull mechanical properties following parietal bone graft harvesting in adults
}

\author{
Pierre Haen, Guillaume Dubois, Patrick Goudot, Thomas Schouman
}

\section{- To cite this version:}

Pierre Haen, Guillaume Dubois, Patrick Goudot, Thomas Schouman. Comparative finite element analysis of skull mechanical properties following parietal bone graft harvesting in adults. Journal of Cranio-Maxillo-Facial Surgery, 2017, 46 (2), pp.329-337. 10.1016/j.jcms.2017.11.020 . hal-02615368

\author{
HAL Id: hal-02615368 \\ https://hal.science/hal-02615368
}

Submitted on 22 May 2020

HAL is a multi-disciplinary open access archive for the deposit and dissemination of scientific research documents, whether they are published or not. The documents may come from teaching and research institutions in France or abroad, or from public or private research centers.
L'archive ouverte pluridisciplinaire HAL, est destinée au dépôt et à la diffusion de documents scientifiques de niveau recherche, publiés ou non, émanant des établissements d'enseignement et de recherche français ou étrangers, des laboratoires publics ou privés. 


\title{
Comparative finite element analysis of skull mechanical properties following parietal bone graft harvesting in adults
}

\author{
Pierre Haen ${ }^{\text {a, b, * }}$, Guillaume Dubois ${ }^{\text {c, d }}$, Patrick Goudot ${ }^{\text {b }}$, Thomas Schouman ${ }^{\text {b }}$ \\ a Service de stomatologie et chirurgie maxillo-faciale, Hôpital Laveran, Boulevard Laveran, 13013, Marseille, France \\ b Service de stomatologie et chirurgie maxillo-faciale, DHU FAST, groupe hospitalier Pitié-Salpêtrière Charles-Foix, AP-HP, 75013, Paris, France \\ ${ }^{c}$ OBL, Materialise Compagny, Châtillon, France \\ d Arts et Métiers, ParisTech, Institut de Biomécanique Humaine Georges Charpak, Paris, France
}

Keywords:

Parietal bone

Finite element analysis

Transplant donor site

Traumatology

Mechanical stress

\begin{abstract}
A B S T R A C T
Introduction: Parietal bone grafts are commonly used in cranio-maxillo-facial surgery. Both the outer and the internal layer of the calvarium can be harvested. The bone defect created by this harvesting may induce significant weakening of the skull that has not been extensively evaluated. Our aim was to evaluate the consequences of parietal bone graft harvesting on mechanical properties of the skull using a finite element analysis.

Methods: Finite elements models of the skull of 3 adult patients were created from CT scans. Parietal external and internal layer harvest models were created. Frontal, lateral, and parietal loading were modeled and von Mises stress distributions were compared.

Results: The maximal von Mises stress was higher for models of bone harvesting, both on the whole skull and at the harvested site. Maximal von Mises stress was even higher for models with internal layer defect.

Conclusions: Harvesting parietal bone modifies the skull's mechanical strength and can increase the risk of skull fracture, mainly on the harvested site. Outer layer parietal graft harvesting is indicated. Graft harvesting located in the upper part of the parietal bone, close to the sagittal suture and with smooth internal edges and corners should limit the risk of fracture.
\end{abstract}

\section{Introduction}

Autologous calvarial bone grafts are commonly used for craniomaxillo-facial reconstructions because of numerous advantages: accessibility, high osseointegration properties with minimal graft resorption and poor donor site complications (Putters et al., 2015; Raulo and Baruch, 1990; Tessier, 1982). Bone grafts harvested from the outer layer of the parietal bone are used most often, but some authors recommend full thickness harvesting and repositioning of the external layer so as to use the internal for grafting (Wolfe et al., 2008), as historically described by Tessier (Tessier et al., 2005). Some authors have reported a non-regeneration of the total thickness of the total parietal bone thickness after graft

\footnotetext{
* Corresponding author. Present address: Service de stomatologie et chirurgie maxillo-faciale, Hôpital Laveran, Boulevard Laveran, 13013, Marseille, France.

E-mail address: pierre.haen@yahoo.fr (P. Haen).
}

harvesting in adults (Chang et al., 2014; Touzet et al., 2011). The case is different with children, who usually present with total regeneration of skull bone after graft harvesting (Barone and Jimenez, 1997; Ghosh et al., 2014). Removing bone from the parietal area decreases the thickness of the calvarium definitively and may potentially affect the skull's mechanical strength. There are currently no clinical data concerning skull trauma following bone graft harvesting in adults. But the authors of more recent studies on animals or fresh cadavers have reported a significant weakening of the harvesting site in case of external layer harvest (Laure et al., 2010, 2011). However, only restricted conclusions can be made from animal-model studies because of anatomical differences between a human skull and an animal skull. Furthermore, these studies addressed only the consequences of an external layer harvesting, since studies on the effect of internal layer harvesting are difficult to conduct with the same methods. In addition, alteration of local rigidity has been assessed, but not its consequences on the overall mechanical behavior of the skull, which is the main issue in 
case of head trauma. The finite element analysis (FEA) offers a costeffective alternative to experimental testing through numerical simulations in a virtual environment. Many authors have reported the validity of FEA, particularly when investigating biomechanical simulations of traumatic craniofacial injuries (Sahoo et al., 2016; Vollmer et al., 2000; Yang et al., 2014)

The primary aim of our study was to evaluate the changes in the mechanical strength of the human skull following parietal bone harvesting, using an FEA. The secondary aim was to compare the effect of outer and inner layer harvesting.

\section{Methods and materials}

\subsection{Model creation}

\subsubsection{Healthy models (Supplemental digital content 1)}

Three finite element models were created from the craniofacial CT scans ( $0.4219 \mathrm{~mm}$ contiguous slicing) of 3 living young male patients free of any bone lesion. CT scans were obtained for unrelated medical reasons (headache, soft tissue infection), and the patients consented to have their data used. CT scans were anonymized. The retrospective use of anonymous clinical data did not require ethical approval at the time of the study, according to national regulations. The acquisition protocol (calibration and spatial marks) was the same for all CT scans. For each CT scan, the DICOM data was extracted for segmentation using Mimics ${ }^{\circledR} 13.1$ (Materialise, Leuven, Belgium). Mandible, cervical vertebrae, and teeth were removed from this first model in order to simplify and accelerate the calculation process. The resulting skull (craniofacial skeleton) was imported into 3-matic ${ }^{\mathbb{B}} 4.4$ (Materialise, Leuven, Belgium) to create a linear tetrahedral volume-meshed model (the properties of each model are listed in Table 1). Young's moduli (elastic moduli) were ted following a Houndsfield-unit correlation rule using Mimics ${ }^{\circledR} 13.1$ (Materialise, Leuven, Belgium). This rule is based on the following relationship between apparent density (measured by voxel intensity in Hounsfield units) and Young's moduli: $E=\mathrm{k} . \rho^{3}$ (Zannoni et al., 1998) where $E$ is the Young's modulus in MPa; $\rho$ is the apparent density in $\mathrm{kg} \mathrm{m}^{-3}$, and $k$ is a coefficient depending of the CT scan calibration (Dubois et al., 2007; Sahoo et al., 2013) with $\mathrm{k}=4249 \mathrm{GPa}\left(\mathrm{g} / \mathrm{cm}^{3}\right)^{-3}$ for our study. A total of 100 values of Young's moduli were assigned. Poisson's ratio was set at 0.3 , as determined previously for bone tissue (Motherway et al., 2009b; Rho et al., 1995; Zannoni et al., 1998) (Mechanical properties and assignment rules of the models are listed in Table 2).

\subsubsection{Harvested models (Supplemental digital content 2)}

Virtual harvestings of the parietal bone were created in each of the previous models using 3-matic ${ }^{\circledR} 4.4$. Two kinds of harvested models were created: one with an external layer defect and a second one with an internal layer defect. All defects corresponded

Table 1

Characteristics of the native models.

\begin{tabular}{llll}
\hline & Model 1 & Model 2 & Model 3 \\
\hline $\begin{array}{l}\text { Gender } \\
\text { Age }\end{array}$ & male & male & male \\
$\begin{array}{c}\text { Parietal bone thickness of } \\
\text { healthy model (non-harvested) } \\
\text { at the center of the theoretic defect (mm) }\end{array}$ & 10 & 33 & 40 \\
$\begin{array}{c}\text { Parietal bone thickness of harvested } \\
\text { model at the center of the defect }\end{array}$ & 5 & 3 & 3 \\
$\quad \begin{array}{l}\text { (mm) } \\
\begin{array}{c}\text { Number of elements of the native } \\
\text { model (unharvested model) }\end{array}\end{array}$ & 520,248 & 433,406 & 528,953 \\
\hline
\end{tabular}

Table 2

Mechanical properties of the cortical and cancellous bone.

\begin{tabular}{lll}
\hline & Cortical bone & Cancellous bone \\
\hline Mass density $\left(\mathrm{kg} / \mathrm{m}^{3}\right)$ & $>1,840$ & $1,000-1,840$ \\
Young Modulus $(\mathrm{MPa})$ & 13,700 & $1,370-1,3700$ \\
Poisson ratio & 0.3 & 0.3 \\
Hounsfield unit & $>3,000$ & $1,000-3,000$ \\
\hline
\end{tabular}

to a $5 \times 5 \mathrm{~cm}$ square (i.e. $25 \mathrm{~cm}^{2}$ area) at the external surface, located in the right parietal bone, $3 \mathrm{~cm}$ away laterally from the sagittal suture and $3 \mathrm{~cm}$ behind the coronal suture. The thickness of the defects was half of the total thickness measured at the center of the squares (Table 1). We considered an optimal bone healing of the external layer with no remaining bone defect around the harvested site and no bone fixation material, for internal harvesting models.

\subsection{Scenarios and boundary conditions (Fig. 1)}

All calculations were made with ABAQUS ${ }^{\circledR} 7.0$ (Simulia, Providence, United States).

We created 3 kinds of scenarios compatible with traffic accidents to simulate plausible traumatic conditions (Sahoo et al. 2016). The first scenario simulated frontal loading with occipital fixity, the second simulated a right side loading with an opposite fixity, and the third simulated parietal loading at the center of the defect with skull base fixity.

We created 4 typical planes to reproduce the same loading conditions for each model: a medial plane corresponding to the sagittal suture; a horizontal plane (Frankfurt plane) passing through the highest node of both ear canals and the lowest node of the left orbit inferior margin; a second horizontal plane, parallel to the previous one but $3 \mathrm{~cm}$ higher; and a frontal plane, perpendicular to the horizontal planes passing through the highest node of both ear canals. These 4 planes allowed defining equivalent loading and fixity areas for each model. All loading scenarios were considered as quasi-static. A 2,200 $\mathrm{N}$ load was applied on a circular area of $165 \mathrm{~mm}^{2}$, corresponding to a loading pressure of $13.3 \mathrm{MPa}$. This value was arbitrarily chosen so as to be sufficient to allow comparison of results among the loading scenarios, but not too high so as to stay in the elastic deformation condition of bone deformation (far from plastic deformation or fracture conditions (Motherway et al., 2009b; Asgharpour et al., 2014)). These are the conditions of an impact due to clumsiness, for example.

The central node was fixed in the 3 degrees of freedom and all the nodes included in the $165 \mathrm{~mm}^{2}$ circle around the central node were locked in the loading direction, to determine the fixity areas. An orthogonal mark was defined at the center point of the loading area, so as to direct the loading charge from the loading point to the fixity area.

\subsubsection{Frontal loading scenario}

The center of the frontal loading area was located in the sagittal plane, $3 \mathrm{~cm}$ above the frontonasal suture; the center of the fixity area was located $3.5 \mathrm{~cm}$ above the external occipital protuberance, in the same sagittal plane.

\subsubsection{Lateral loading scenario}

The center of the lateral loading area was located on the right temporal bone, at the intersection between the frontal plane and the highest horizontal plane. The center of the fixity area was located at the same place on the left temporal bone. 


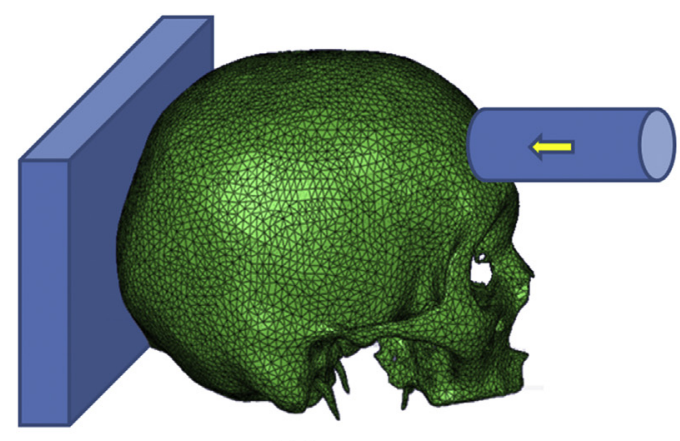

(A)

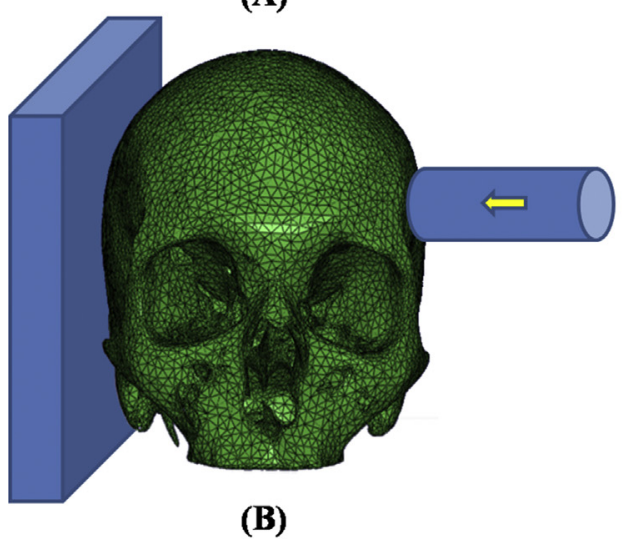

(B)

Fig. 1. Loading scenarios. (A) Frontal loading scenario. (B) Lateral loading scenario. (C) Parietal loading scenario.

\subsubsection{Parietal loading scenario}

The center of the parietal loading area was located at the center of the external surface of the defect, for external layer harvesting models, and on the external surface of the parietal bone at the same location for healthy and internal layer harvesting models.

27 finite element analysis calculations were done, including 3 scenarios for each of the 3 models. The von Mises stress (vMs) distribution, maximal vMs of the overall skull and at the center of the defect (or theoretic defect for healthy models) were compared.

\section{Results (Tables 3 and 4 )}

\subsection{Frontal loading scenario (Figs. 2 and 3)}

\subsubsection{Healthy models}

The highest vMs (range 30.0-53.1 MPa) could be noted at the loading and the fixity area. Other high VMs areas were observed in calvarium, spread over 2 lines: the first around the temporo-

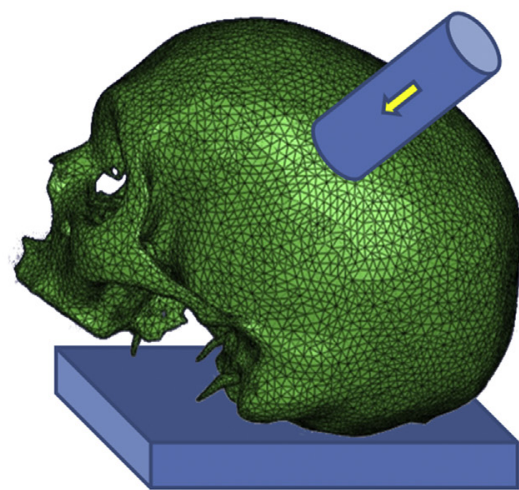

(C) parietal suture (4.1-8.5 MPa) and the second with lower vMs around the sagittal suture (2.8-5.3 MPa). Stress concentration was also observed on the skull base along the foramen magnum. Very little stress was observed in the theoretical defect area of the parietal bone. The highest overall skull vMs (range 30.0-53.0 MPa) and the vMs at the theoretical bone defect (range 2.5-3.6 MPa) were different for each model, but the overall mechanical behavior was comparable for all 3 models.

\subsubsection{External layer harvesting models}

Comparable mechanical behavior was observed for the 3 external layer harvesting models. The highest vMs areas were also located in the loading and fixity areas (range 38.3-62.1 MPa), but a stress concentration area was observed (range 3.5-4.7 MPa) in the lower part of the parietal defect, with an upward deviation of the temporo-parietal vMs concentration line, to reach the harvesting area. The highest vMs values were increased $(+5.7 \%$ to $+27.6 \%$ for the overall skull, +11.1 to $+60 \%$ at the defect area) compared to the healthy models.

Table 3

Maximum von Mises stress observed in the complete skull with various loading scenarios (MPa)

\begin{tabular}{|c|c|c|c|c|c|}
\hline & & VM s frontal loading (MPa) & VMs lateral loading (MPa) & VMs parietal loading (MPa) & Mean \\
\hline \multirow[t]{3}{*}{ Model 1} & Healthy model & 53.0 & 132.5 & 219.8 & 135.1 \\
\hline & External layer harvest m. & 62.1(+17.1\%) & $135.9(+2.6 \%)$ & $237.1(+7.9 \%)$ & $145.0(+7.3 \%)$ \\
\hline & Internal layer harvest m. & $65.0(+22.6 \%)$ & $210.0(+58.5 \%)$ & $246.6(+\mathbf{1 2 . 2} \%)$ & $173.9(+\mathbf{2 8 . 7 \%})$ \\
\hline \multirow[t]{3}{*}{ Model 2} & Healthy model & 36.6 & 185.8 & 87.2 & 103.2 \\
\hline & External layer harvest m. & $38.7(+5.7 \%)$ & $194.5(+4.7 \%)$ & $122.7(+\mathbf{4 0 . 7 \%})$ & $118.6(+\mathbf{1 4 . 9} \%)$ \\
\hline & Internal layer harvest m. & $56.9(+55.5 \%)$ & $196.6(+\mathbf{5 . 8 \%})$ & $178.0(+\mathbf{1 0 4 . 1 \%})$ & $144.8(+\mathbf{4 0 . 3 \%})$ \\
\hline \multirow[t]{3}{*}{ Model 3} & Healthy model & 30.0 & 54.7 & 60.3 & 48.3 \\
\hline & External layer harvest m. & $38.3(+27.6 \%)$ & $57.6(+5.3 \%)$ & $68.2(+13.1 \%)$ & $54.7(+13.2 \%)$ \\
\hline & Internal layer harvest m. & $43.4(+\mathbf{4 4 . 7 \% )}$ & $59.8(+9.3 \%)$ & $81.7(+35.5 \%)$ & $61.6(+27.5 \%)$ \\
\hline
\end{tabular}

Bold characters correspond to the increase (in \%) of von Mises stress from healthy model. 
Table 4

Maximum von Mises stress observed in the defect area (effective area for harvested models and theoretic for healthy models). (MPa).

\begin{tabular}{|c|c|c|c|c|c|}
\hline & & VM s frontal loading (MPa) & VMs lateral loading (MPa) & VMs parietal loading (MPa) & Mean \\
\hline \multirow[t]{3}{*}{ Model 1} & Healthy model & 2.5 & 7.7 & 28.6 & 12.9 \\
\hline & External layer harvest $\mathrm{m}$. & $3.5(+40 \%)$ & $9.2(+19.5 \%)$ & $55.1(+92.7 \%)$ & $22.6(+75.2 \%)$ \\
\hline & Internal layer harvest m. & $3.7(+48 \%)$ & $10.9(+41.6 \%)$ & $56.8(+98.6 \%)$ & $23.8(+84.5 \%)$ \\
\hline \multirow[t]{3}{*}{ Model 2} & Healthy model & 3.0 & 20.0 & 45.4 & 22.8 \\
\hline & External layer harvest $\mathrm{m}$. & $4.8(+60 \%)$ & $24.5(+22.5 \%)$ & $78.7(+73.3 \%)$ & $36(+\mathbf{5 7 . 9 \%})$ \\
\hline & Internal layer harvest m. & $5.5(+83.3 \%)$ & $32.6(+63 \%)$ & $82.9(+82.6 \%)$ & $40.3(+76.7 \%)$ \\
\hline \multirow[t]{3}{*}{ Model 3} & Healthy model & 3.6 & 6.0 & 35.2 & 14.9 \\
\hline & External layer harvest m. & $4.0(+11.1 \%)$ & $7.8(+30 \%)$ & $57.9(+64.5 \%)$ & $23.2(+\mathbf{5 5} .7 \%)$ \\
\hline & Internal layer harvest m. & $4.1(+13.8 \%)$ & $11.8(+96.7 \%)$ & $81.7(+\mathbf{1 3 2 . 1} \%)$ & $32.5(+\mathbf{1 1 8 . 1 \%})$ \\
\hline
\end{tabular}

Bold characters correspond to the increase (in \%) of von Mises stress from healthy model.

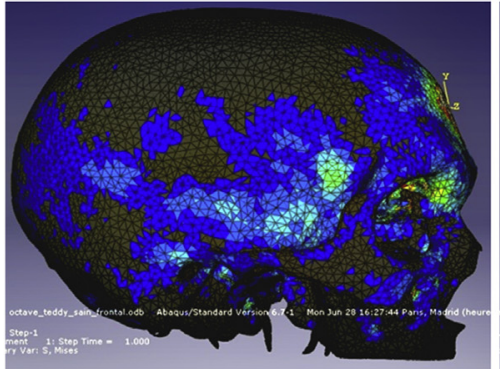

(A)

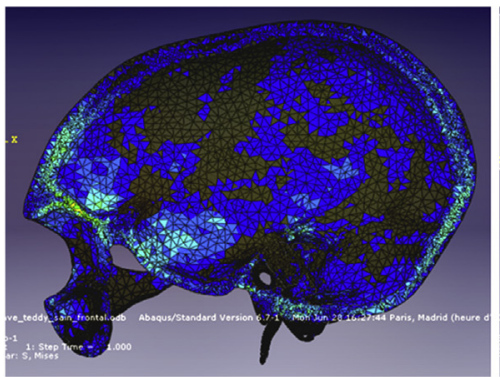

(B)

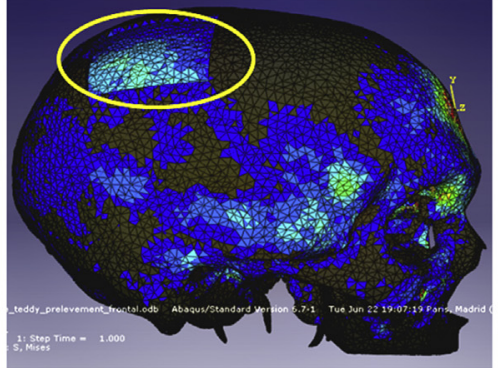

(C)

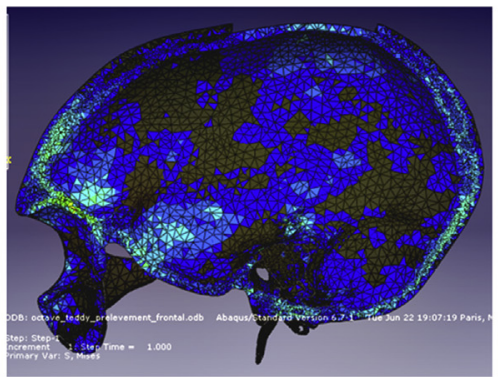

(D)

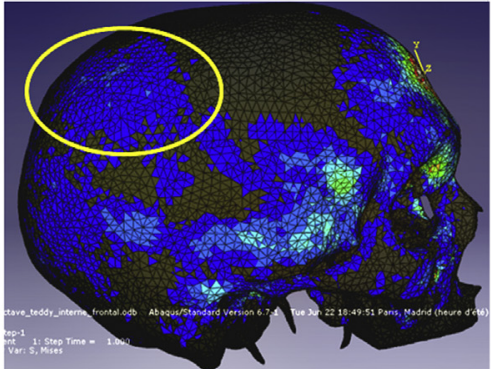

(E)

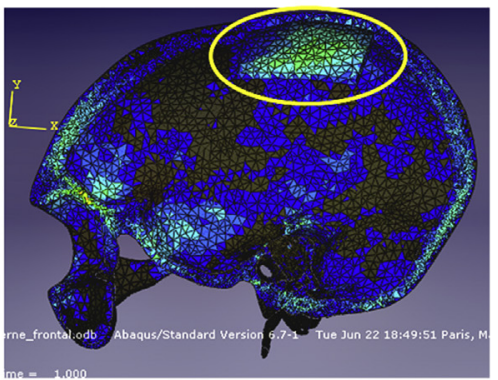

(F)

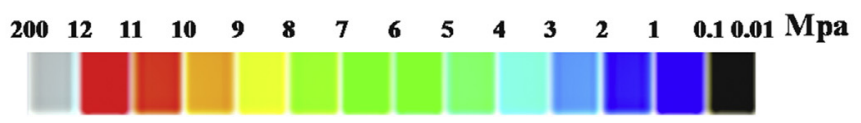

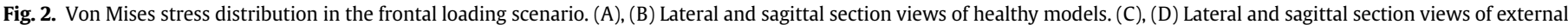

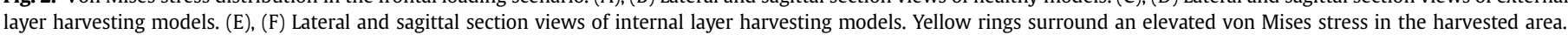

\subsubsection{Internal layer harvesting models}

Similar alterations of the mechanical behavior were observed for the internal layer harvesting models. However, the highest vMs values (range 43.4-64.0 MPa) were superior to those of the external layer harvesting models $(+22.6 \%$ to $+55.5 \%)$ versus healthy models, $+17.1 \%$ to $+49.8 \%$ versus external layer harvesting model. The highest vMs values at the defect area (range $3.7-5.5 \mathrm{Mpa})$ were superior to those of the external harvesting models ( $+13.8 \%$ to $+83.3 \%$ ) versus healthy models, +2.7 to $+23.3 \%$ versus external layer harvesting models.

\subsection{Lateral loading scenario (Figs. 4 and 5)}

\subsubsection{Healthy models}

The highest vMs areas (range 54.7-185.8 MPa) were located at the loading and fixity areas, and essentially in the skull base around the foramen magnum. Little stress was observed in the theoretical parietal bone defect area (6.0-20.0 MPa).

\subsubsection{External layer harvesting models}

A high-level vMs (7.7-24.5 MPa) area was observed at the defect area, particularly in the inferior part. The highest vMs values of the overall skull (range 57.6-194.5 MPa) and at the defect were superior to those of the healthy models $(+2.6 \%$ to $+5.3 \%$ for the overall skull; $+19.5 \%$ to $+30 \%$ at the defect area). The highest stress values were located at the lower half of the harvesting site.

\subsubsection{Internal layer harvesting models}

Similar modifications were observed with a high-level vMs area (10.9-32.6 MPa) in the lower half of the defect. The highest vMs values of the overall skull (range $59.8-210.0 \mathrm{MPa}$ ) and at the harvested site were superior to those of healthy models and of external layer harvesting models, as in frontal loading $(+5.8 \%$ to $+58.5 \%$ versus healthy model, +1.1 to $+55.9 \%$ versus external layer harvesting model for overall skull; $+41.6 \%$ to $+96.7 \%$ versus healthy model, $+22.1 \%$ to $+66.7 \%$ versus external layer harvesting model at the harvested site). 


\section{Frontal loading scenario}

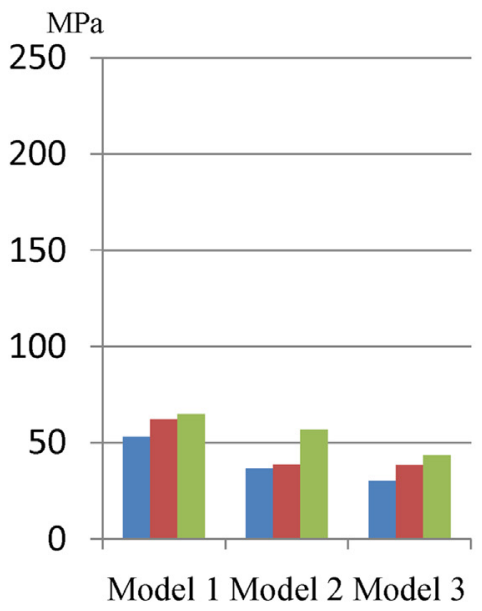

(A)

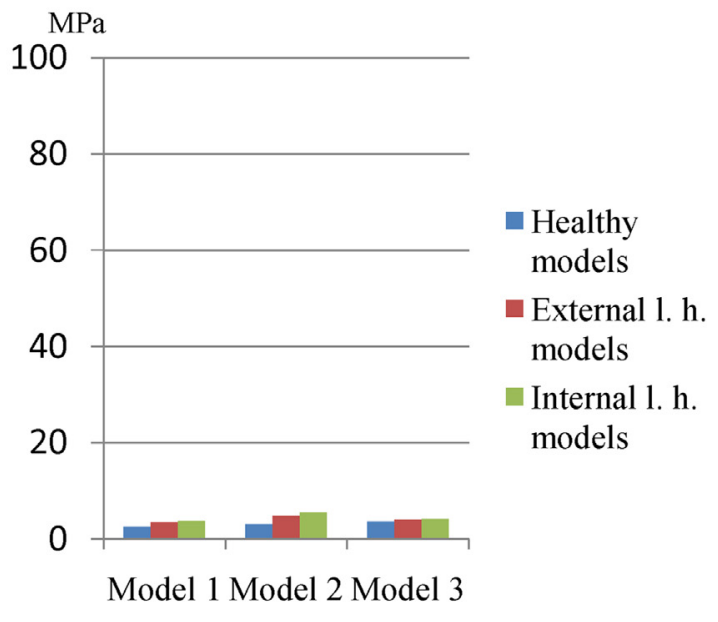

(B)

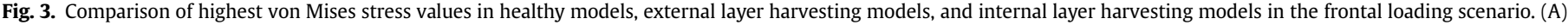
Highest von Mises stress value of the overall skull. (B) Highest von Mises stress value at the defect area.

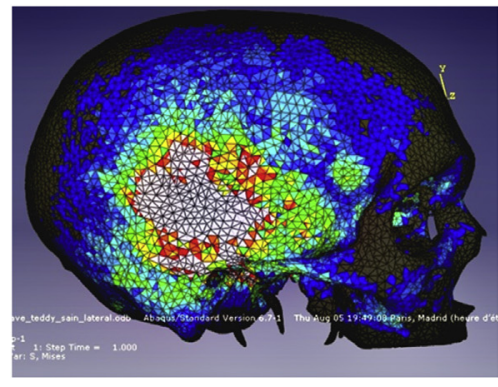

(A)

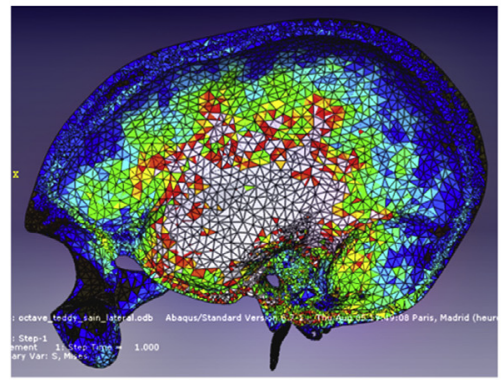

(B)

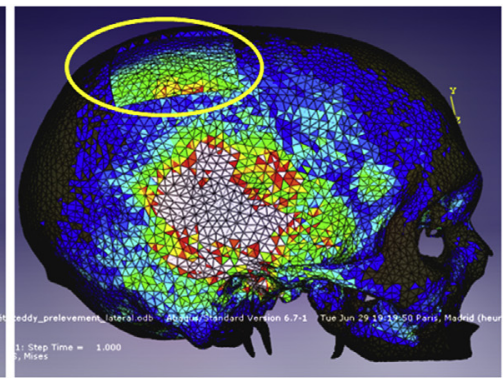

(C)

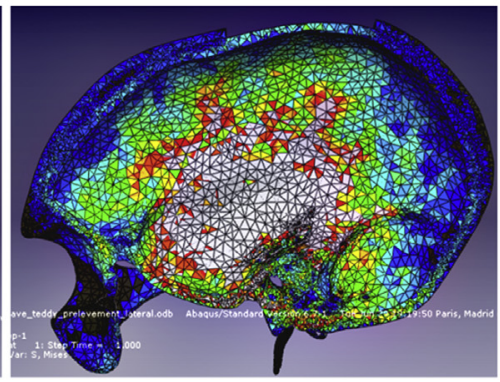

(D)

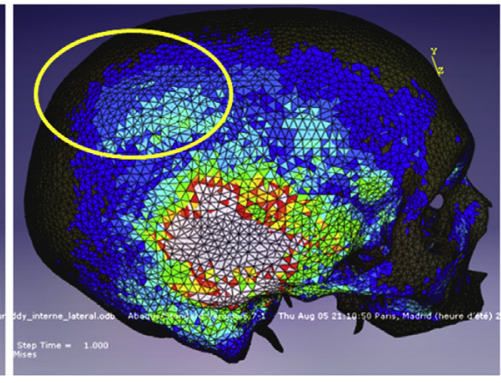

(E)

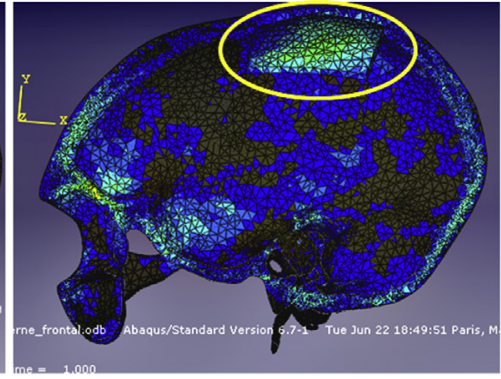

(F)

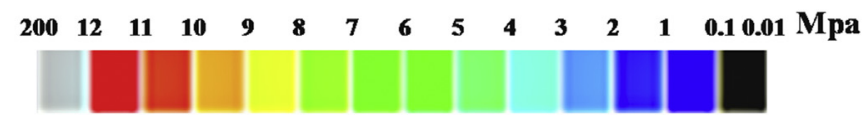

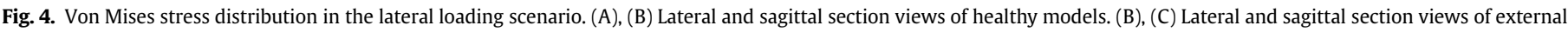
layer harvesting models. (E), (F) Lateral and sagittal section views of internal layer harvesting models. Yellow rings surround an elevated von Mises stress in harvested area.

\subsection{Parietal loading scenario (Figs. 6 and 7)}

\subsubsection{Healthy models}

The highest vMs areas (range 60.3-219.8 MPa) were located at the loading (theoretical defect area) and fixed areas. A high-level vMs (5.5-15.3 $\mathrm{MPa}$ ) area was observed around the temporoparietal suture.

\subsubsection{External layer harvesting models}

The high-level vMs area was larger than in healthy models, especially in the lower part of the defect. The highest overall skull vMs (range 68.2-237.1 MPa) and highest defect vMs values (range $55.1-78.7 \mathrm{MPa}$ ) were increased compared to healthy models $(+7.9 \%$ to $+40.7 \%$ for the overall skull; $+64.5 \%$ to $+92.7 \%$ at the harvested site). 


\section{Lateral loading scenario}

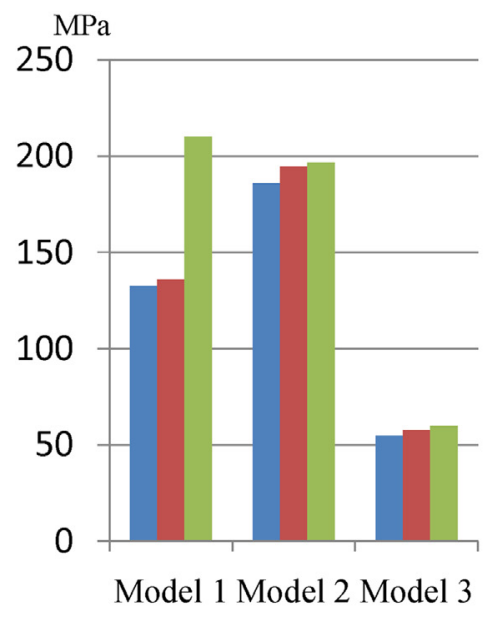

(A)

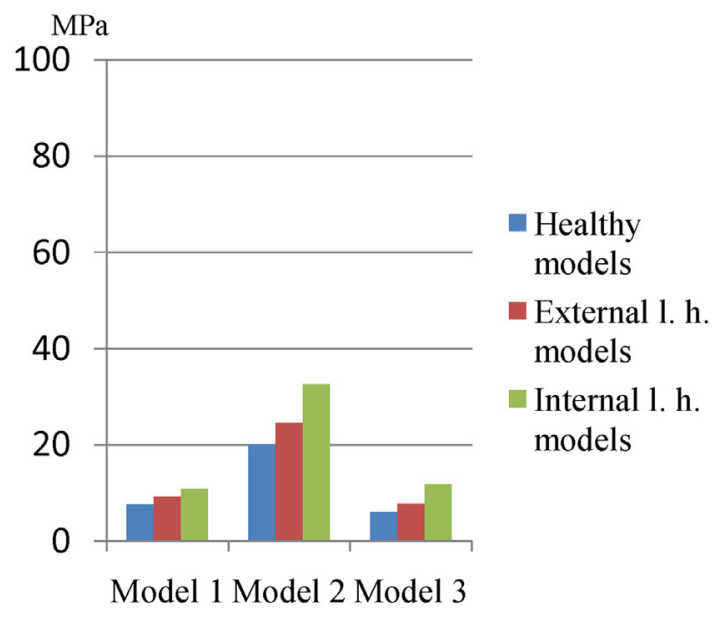

(B)

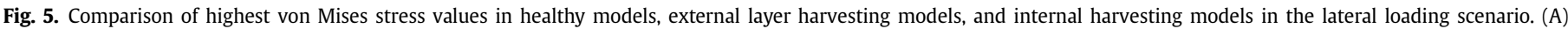
Highest von Mises stress value of the overall skull. (B) Highest von Mises stress value at the defect area.

\subsubsection{Internal layer harvesting models}

The high-level vMs area was even larger than in the external layer harvesting model. Similarly, the highest overall vMs (range 81.7-246.6 Mpa) and highest defect vMs values (56.8-82.9 Mpa) were higher than in the external layer harvesting models $(+12.2 \%$ to $+104.1 \%$ versus healthy model, +4.3 to $+63.4 \%$ versus external layer harvesting model for the overall skull; $+82.6 \%$ to $+132.1 \%$ versus healthy model, $+5.9 \%$ to $+67.6 \%$ versus external layer harvesting model at the harvested site).

\section{Discussion}

\subsection{Modifications of skull mechanical strength}

This finite element study results proved that harvesting parietal bone induced modifications of the skull mechanical strength. The vMs distribution changes after creating a split-thickness parietal bone defect, revealing a significant weakening at the harvested area, particularly in the inferior part, in all scenarios, including in case of loading conditions both directly on the harvesting site or away from it. A decreased mechanical strength was also observed for the whole skull structure after harvesting. This high-level vMs area was larger for the models with an internal layer defect. We also observed an increase of the highest vMs values for the defect area and for the whole skull.

\subsection{Finite element analysis}

FEA is a validated method for the evaluation of the mechanical behavior of the mandible (Vollmer et al., 2000), of the maxilla (Huang et al., 2016), of the zygoma (Schaller et al., 2011) and of the skull (Li et al., 2015; Sahoo et al., 2013, 2016; Yang et al., 2014). Highly refined models provide more reliable simulations and accurate analyses. The total number of elements in our models ranged between 430,000 and 530,000 , higher than that of previously reported models in cranio-facial FEA studies (Autuori et al., 2006; Motherway et al., 2009a; Zong et al., 2006). Determining material parameters according to local bone radiological characteristics allowed us to create truer-to-life models, the realism of our models, as reported the most recent studies (Sahoo et al., 2013, 2016). Furthermore, including 3 different models from 3 different CT scans increased the power of our study, since the 3 models exhibited similar patterns. Our models were further validated by simulating an additional scenario. The latter consisted in a wide spread anteroposterior loading applied to the central part of the face. The aim was to compare the vMs distribution in that scenario with typical Le Fort cranio-facial fractures associated with this type of impact (see figure in Supplemental digital content 3).

\subsection{Fracture risk}

Recently, Sahoo et al. have shown that the skull internal energy was the best suitable parameter for the prediction of skull fracture (Sahoo et al., 2016). In elastic deformation conditions, the internal energy value is related to the vMs values through elastic properties. Thus, an increased maximal vMs value is also associated with an increased risk of bone fracture. Other authors have also reported that high stress areas corresponded to high risk of fracture areas (Huempfner-Hierl et al., 2014, 2015). Our results prove that parietal bone defect increases the risk of skull fracture, and that an internal calvarial layer defect is associated with a higher risk of fracture. The internal layer of the parietal bone is thinner than the outer layer (Sullivan and Smith, 1989). This could suggest that internal defects would less affect the biomechanical behavior of the skull than external ones, contrary to our findings. However, thickness is not the only factor determining the risk of fracture. Skull geometry, sutures aspect, rigidity and density also play an important role, and some authors suggested that the internal layer of the parietal bone was stiffer than the outer layer (Bandak et al., 1995; Laure et al., 2010; Ruan and Prasad, 2001; Thollon et al., 2013). Furthermore, models with an internal layer are built on the assumption that complete bone healing of the outer layer is achieved, which is not always the case in routine clinical practice (Chang et al., 2014). Our simulations also showed the highest vMs at the internal edges of the harvested site. This can be explained by a stress concentration due to a brutal change of geometry at the edges of the harvested 


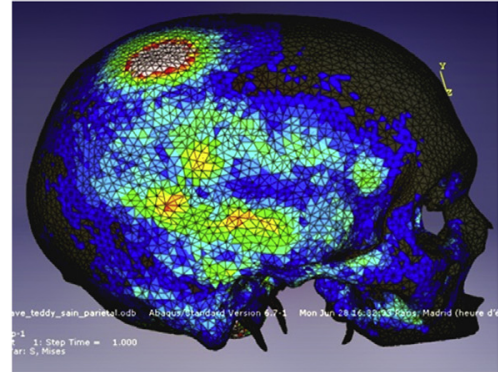

(A)

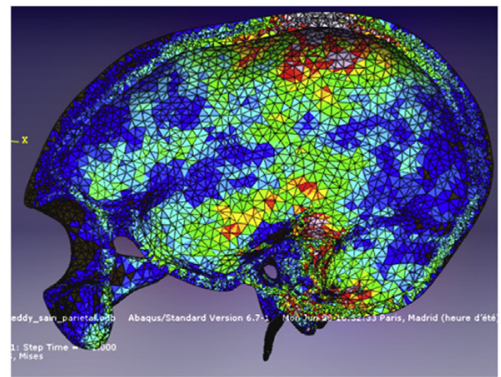

(B)

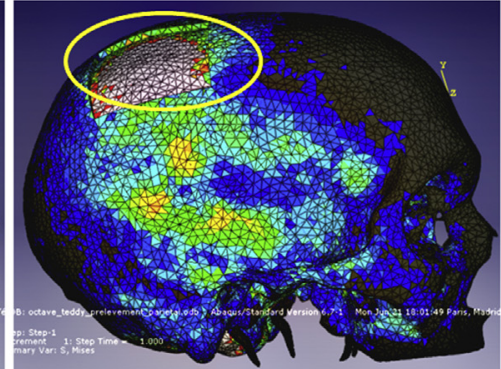

(C)

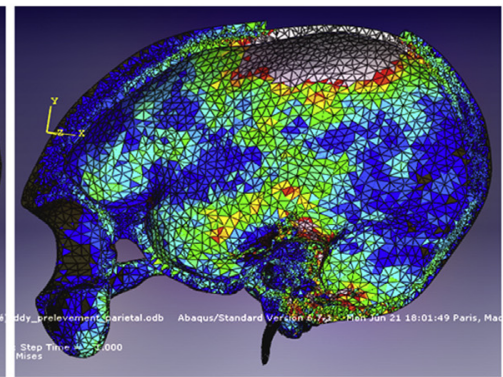

(D)

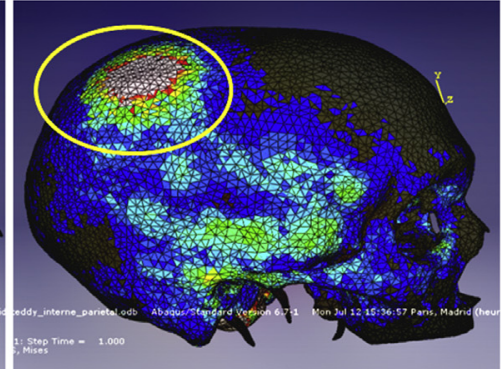

(E)

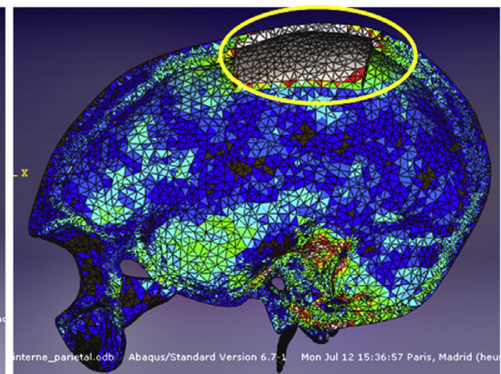

(F)

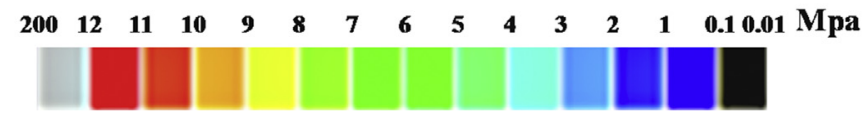

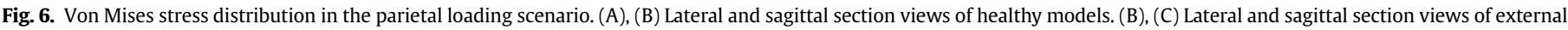

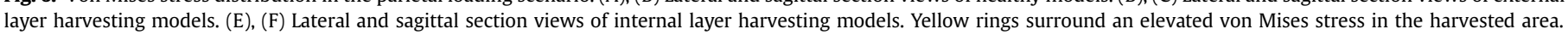

\section{Parietal loading scenario}

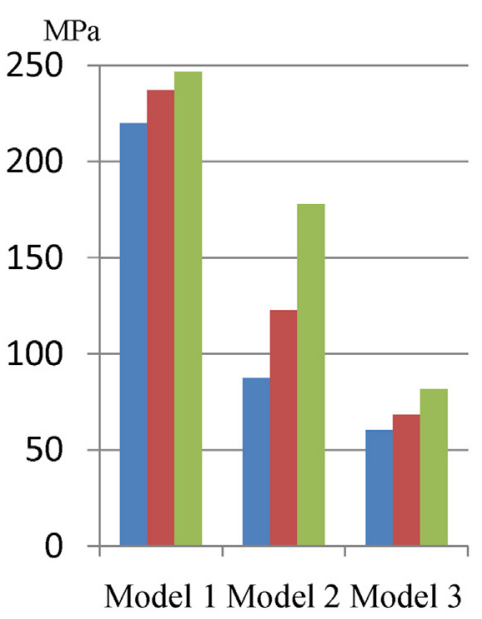

(A)

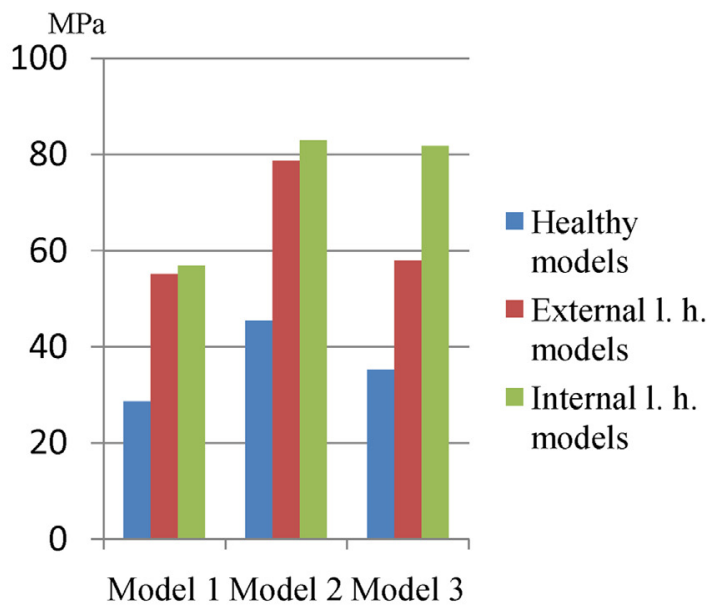

(B)

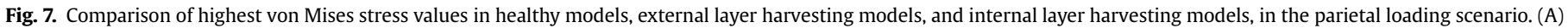
Highest von Mises stress value of the overall skull. (B) Highest von Mises stress value at the defect area.

site. Obtaining smoother internal edges and corners during graft harvesting should allow decreasing this stress concentration effect.

The elevated stress area in the inferior part of the defect proves there is a local weakness associated with a higher risk of fracture in this area. This correlates with the geometry of the parietal bone, the thickness of which is greater in the upper and posterior region (Hardesty and Marsh, 1990; Jung et al., 2003).
The variability of values obtained among our models can be explained partly by the difference in parietal bone thickness and mineral density, depending on gender, age, and ethnical origins (Jones et al., 2015; Lillie et al., 2015; Lynnerup et al., 2005), and by the fact that the strength of the skull is influenced by its shape and its size, with great individual variability (Sahoo et al., 2015). 


\subsection{Limitations/weaknesses of our model}

Our models were not those of true to life traumatic conditions, since the loading regimens were all quasi-static. They did not allow analyzing the result of the impact or energy transfer, which would be closer to real traumatic conditions. However, using static conditions limited the risk of numerical error due to diverging simulations and accelerated the calculation. Our simulation corresponded to a mechanical test conducted with a press. However, our models provided a highly refined analysis of the mechanical property changes. Our models also predicted a greater maximal vMs higher than the admissible stress for human bone (Davy and Jepsen, 2001) due to their elastic properties. These limitations are also mitigated by the comparative character of our study.

The size of the bone defect $\left(25 \mathrm{~cm}^{2}\right)$ we used in the model was representative of common clinical practice (Touzet et al., 2011). Our findings suggest that mechanical property changes could vary depending on the size and shape of the defect.

Since the first description of calvarial bone harvest using burrs, chisels, hammer, and trepan (Raulo and Baruch, 1990; Tessier, 1982), other tools have been developed, including oscillating saw, bone scraper (Schortinghuis et al., 2012), and piezoelectric devices (Gonzalez-Lagunas and Mareque, 2007). Our model was built on the basis of an ideal harvesting with no irregularity and with a homogeneous thickness of the remaining parietal bone, thus underestimating mechanical behavior changes as compared to actual clinical practice. The irregularities and variable thickness of the bone as well as the possible cracks due to the use of bone chisels, or incomplete healing of bicortical burr holes may modify the mechanical behavior of the skull more importantly. However, the comparative design of our study allowed drawing valid conclusions.

The potential role of soft tissues (scalp, brain, meninges, cerebro-spinal liquid) on the overall mechanical behavior of the skull was not taken into account in our models. Despite a possible dampening effect in case of an impact on the skull, this soft tissue effect is unlikely to differ significantly from one model to the next (Huempfner-Hierl et al., 2015).

Nowadays, even if some authors have reported loss of strength of the skull after outer layer parietal bone harvesting (Laure et al., 2010), no clinical history has ever been reported in referenced literature concerning traumatic skull fracture in adults following parietal graft. This is due to the scarcity of the event or, possibly, to the fact that in case of lethal trauma by skull injury an obvious parietal bone graft is not systematically investigated. Therefore, it is difficult to compare our findings with routine clinical care because no data are available.

\section{Conclusions}

Split-thickness parietal bone harvesting significantly modifies the skull's mechanical properties and increases the risk of skull fractures, particularly in case of internal calvarial layer harvesting. This risk may be minimized by following recommendations suggested according to our findings: 1) outer layer harvesting of the calvarial bone should be elected rather than internal harvesting, and 2) the harvesting site should be preferentially located in the upper part of the parietal bone, near the sagittal suture, and smooth internal edges and corners should be achieved. A rectangular shape with the long side parallel to the sagittal suture should be a good option.

\section{Funding source}

This research did not receive any specific grant from funding agencies in the public, commercial, or not-for-profit sectors.

\section{Conflicts of interest}

No financial support or benefits have been received by me or any co-authors, by any member of my (our) immediate family or any individual or entity with whom or with which I (we) have a relationship from any commercial source which is related directly or indirectly to the scientific work which is reported on in the article.

\section{Acknowledgements}

The authors are particularly grateful for the language assistance given by Dr. Pierre-Emmanuel Colle.

\section{Appendix A. Supplementary data}

Supplementary data related to this article can be found at https://doi.org/10.1016/j.jcms.2017.11.020.

\section{References}

Asgharpour Z, Baumgartner D, Williger R, Graw M, Peldschus S: The validation and application of a finite element human head model for frontal skull fracture analysis. J Mech Behav Biomed Mater 33: 16-23, 2014

Autuori B, Bruyere-Garnier K, Morestin F, Brunet M, Verriest JP: Finite element modeling of the head skeleton with a new local quantitative assessment approach. IEEE Trans Biomed Eng 53: 1225-1232, 2006

Bandak FA, Vander Vorst MJ, Stuhmiller LM, Mlakar PF, Chilton WE, Stuhmiller JH: An imaging-based computational and experimental study of skull fracture: finite element model development. J Neurotrauma 12: 679-688, 1995

Barone CM, Jimenez DF: Split-thickness calvarial grafts in young children. J Craniofac Surg 8: 43-47, 1997

Chang TJ, Choi JW, Ra YS, Hong SH, Cho YH, Koh KS: Changes in graft thickness after skull defect reconstruction with autogenous split calvarial bone graft. J Craniofac Surg 25: 1241-1244, 2014

Davy DT, Jepsen KJ: Bone damage mechanics. In: Cowin SC (ed.), Bone mechanics handbook, 2nd ed. Boca Raton: CRC Press, 788-799, 2001

Dubois G, Daas M, Bonnet AS, Lipinski P: Biomechanical study of a prosthetic solution based on an angled abutment: case of upper lateral incisor. Med Eng Phys 29: 989-998, 2007

Ghosh TD, Skolnick G, Nguyen DC, Sun H, Patel K, Smyth MD et al: Calvarial thickness and diploic space development in children with sagittal synostosis as assessed by computed tomography. J Craniofac Surg 25: 1050-1055, 2014

Gonzalez-Lagunas J, Mareque J: Calvarial bone harvesting with piezoelectric device. J Craniofac Surg 18: 1395-1396, 2007

Hardesty RA, Marsh JL: Craniofacial onlay bone grafting: a prospective evaluation of graft morphology, orientation, and embryonic origin. Plast Reconstr Surg 85 5-14, 1990 Discussion 15

Huang SF, Lo LJ, Lin CL: Biomechanical optimization of a custom-made positioning and fixing bone plate for Le Fort I osteotomy by finite element analysis. Comput Biol Med 68: 49-56, 2016

Huempfner-Hierl H, Bohne A, Schaller A, Wollny G, Hierl T: Does facial soft tissue protect against zygomatic fractures? Results of a finite element analysis. Head Face Med 11: 21, 2015

Huempfner-Hierl $\mathrm{H}$, Schaller A, Hemprich A, Hierl T: Biomechanical investigation of naso-orbitoethmoid trauma by finite element analysis. Br J Oral Maxillofac Surg 52: 850-853, 2014

Jones DA, Urban JE, Lillie EM, Stitzel JD: Skull thickness morphing for an age and sex specific FE model of the skull. Biomed Sci Instrum 51: 173-180, 2015

Jung YS, Kim HJ, Choi SW, Kang JW, Cha IH: Regional thickness of parietal bone in Korean adults. Int J Oral Maxillofac Surg 32: 638-641, 2003

Laure B, Petraud A, Sury F, Tranquart F, Goga D: Resistance of the sheep skull after a monocortical cranial graft harvest. J Craniomaxillofac Surg 40: 261-265, 2011

Laure B, Tranquart F, Geais L, Goga D: Evaluation of skull strength following parietal bone graft harvest. Plast Reconstr Surg 126: 1492-1499, 2010

Li Z, Liu W, Zhang J, Hu J: Prediction of skull fracture risk for children 0-9 month old through validated parametric finite element model and cadaver test reconstruction. Int J Leg Med 129: 1055-1066, 2015

Lillie EM, Urban JE, Lynch SK, Weaver AA, Stitzel JD: Evaluation of skull cortica thickness changes with age and sex from computed tomography scans. J Bone Miner Res 31: 299-307, 2015

Lynnerup N, Astrup JG, Sejrsen B: Thickness of the human cranial diploe in relation to age, sex and general body build. Head Face Med 1: 13, 2005

Motherway J, Doorly MC, Curtis M, Gilchrist MD: Head impact biomechanics simulations: a forensic tool for reconstructing head injury? Leg Med Tokyo 11(Suppl. 1): S220-S222, 2009a

Motherway JA, Verschueren P, Van der Perre G, Vander Sloten J, Gilchrist MD: The mechanical properties of cranial bone: the effect of loading rate and cranial sampling position. J Biomech 42: 2129-2135, 2009b 
Putters TF, Schortinghuis J, Vissink A, Raghoebar GM: A prospective study on the morbidity resulting from calvarial bone harvesting for intraoral reconstruction. Int J Oral Maxillofac Surg 44: 513-517, 2015

Raulo Y, Baruch J: Use of the calvarium for bone grafting in cranio-maxillo-facia surgery. Chirurgie 116: 359-362, 1990

Rho JY, Hobatho MC, Ashman RB: Relations of mechanical properties to density and CT numbers in human bone. Med Eng Phys 17: 347-355, 1995

Ruan J, Prasad P: The effects of skull thickness variations on human head dynamic impact responses. Stapp Car Crash J 45: 395-414, 2001

Sahoo D, Deck C, Yoganandan N, Willinger R: Anisotropic composite human skull model and skull fracture validation against temporo-parietal skull fracture. J Mech Behav Biomed Mater 28: 340-353, 2013

Sahoo D, Deck C, Yoganandan N, Willinger R: Development of skull fracture criterion based on real-world head trauma simulations using finite element head model. J Mech Behav Biomed Mater 57: 24-41, 2016

Sahoo D, Deck C, Yoganandan N, Willinger R: Influence of stiffness and shape of contact surface on skull fractures and biomechanical metrics of the human head of different population underlateral impacts. Accid Anal Prev 80: 97-105, 2015

Schaller A, Voigt C, Huempfner-Hierl $H$, Hemprich A, Hierl T: Transient finite element analysis of a traumatic fracture of the zygomatic bone caused by a head collision. Int J Oral Maxillofac Surg 41: 66-73, 2011

Schortinghuis J, Putters TF, Raghoebar GM: Safe harvesting of outer table parietal bone grafts using an oscillating saw and a bone scraper: a refinement of technique for harvesting cortical and "cancellous"-like calvarial bone. J Oral Maxillofac Surg 70: 963-965, 2012
Sullivan WG, Smith AA: The split calvarial graft donor site in the elderly: a study in cadavers. Plast Reconstr Surg 84: 29-31, 1989

Tessier P: Autogenous bone grafts taken from the calvarium for facial and cranial applications. Clin Plast Surg 9: 531-538, 1982

Tessier P, Kawamoto H, Posnick J, Raulo Y, Tulasne JF, Wolfe SA: Taking calvaria grafts, either split in situ or splitting of the parietal bone flap ex vivo-tools and techniques: V. A 9650-case experience in craniofacial and maxillofacial surgery. Plast Reconstr Surg 116: 54S-71S, 2005 Discussion 92S-94S

Thollon L, Llari M, Andre L, Adalian P, Leonetti G, Piercecchi-Marti MD: Biomechanical analysis of skull fractures after uncontrolled hanging release. Forensic Sci Int 233: 220-229, 2013

Touzet S, Ferri J, Wojcik T, Raoul G: Complications of calvarial bone harvesting for maxillofacial reconstructions. J Craniofac Surg 22: 178-181, 2011

Vollmer D, Meyer U, Joos U, Vegh A, Piffko J: Experimental and finite element study of a human mandible. J Craniomaxillofac Surg 28: 91-96, 2000

Wolfe SA, Ghurani R, Podda S, Ward J: An examination of posttraumatic, postsurgical orbital deformities: conclusions drawn for improvement of primary treatment. Plast Reconstr Surg 122: 1870-1881, 2008

Yang B, Tse KM, Chen N, Tan LB, Zheng QQ Yang HM, et al: Development of a finite element head model for the study of impact head injury. Biomed Res Int 2014: 408278, 2014

Zannoni C, Mantovani R, Viceconti M: Material properties assignment to finite element models of bone structures: a new method. Med Eng Phys 20: 735-740, 1998

Zong Z, Lee HP, Lu C: A three-dimensional human head finite element model and power flow in a human head subject to impact loading. J Biomech 39: 284-292, 2006 